\title{
RESÍDUOS ORGÂNICOS: AVALIAÇÃO, TRATAMENTO E POTENCIAL DE USO AGRONÔMICO
}

\author{
Bianca Alves Lopes ${ }^{1}$; Luciano Mendes Souza Vaz (in memoriam) ${ }^{2}$ \\ 1. Bolsista PIBIC/CNPq, Graduando em Bacharelado em Ciências Biológicas, Universidade Estadual de Feira de \\ Santana, e-mail: bibialopes4@gmail.com \\ 2. Orientador, Departamento de Ciências Biológicas, Universidade Estadual de Feira de Santana, e-mail: \\ lucianovaz@yahoo.com.br
}

\section{PALAVRAS-CHAVE: Respirometria, Degradabilidade, Compostagem. INTRODUÇÃOO}

Nas décadas de 40 e 50 do século XX, o sistema capitalista se desenvolveu muito rápido, incutindo nas pessoas a cultura do consumismo, e estimulou em larga escala a produção de itens descartáveis. Este padrão de produção e consumo tem sido agravado nas últimas décadas com a mudança do perfil essencialmente rural da sociedade para um ambiente predominantemente urbano (Taschner \& Bogus, 1986).

Dos métodos utilizados atualmente para o tratamento dos resíduos orgânicos, a compostagem tem-se mostrado uma técnica confiável e com resultados satisfatórios. É uma forma de tecnologia apropriada no que diz respeito ao reaproveitamento de resíduos orgânicos dos mais diversos tipos.

Visto a grande importância da compostagem no que se refere à reutilização dos resíduos orgânicos, este estudo utiliza a compostagem como mecanismo de decomposição de resíduos de casca de laranja e poda oriundos do campus da Universidade Estadual de Feira de Santana- Ba, analisando a qualidade do composto e o seu andamento por meio de análises físico-químicas, e por fim, aplicar o novo composto em uma plantação.

\section{MATERIAL E MÉTODOS OU METODOLOGIA (ou equivalente)}

O desenvolvimento da pesquisa foi realizado na UEFS na área de compostagem localizada na Equipe de Estudos e Educação Ambiental (EEA) durante um período de 45 dias. Após a montagem de seis pilhas, três de casca de laranja e três de poda, foram analisados no Laboratório de Saneamento Básico da mesma instituição, a qualidade do composto e o seu andamento por meio da medição de nitrogênio, carbono e $\mathrm{pH}$ e observando, através da respirometria, o desprendimento do gás carbônico como indicador da decomposição dos resíduos orgânicos por meio dos agentes microscópicos, como fungos e bactérias. Também foi medida a temperatura diária das pilhas com um termômetro eletrônico.

\section{RESULTADOS E/OU DISCUSSÃO (ou Análise e discussão dos resultados)}

Os resultados obtidos da análise do Tratamento de Poda foram esperados, já que não avançou na degradação, por ser um material mais difícil de se decompor quando comparado ao Tratamento de casca de Laranja que obteve um aumento nos níveis de nitrogênio. Já os dados adquiridos nas análises de $\mathrm{pH}$ do Tratamento com casca Laranja não foram adequados no tempo 0 pois foi observado um valor alto para o início da decomposição, que foi o mesmo valor do nível final 8,4. Enquanto o pH do Tratamento com Poda não obteve variação, indicando baixa de nutrientes. Os efeitos da análise da evolução do dióxido de carbono foram aceitáveis para o Tratamento com Poda e do Tratamento com casca de Laranja, sendo notado o aumento da atividade biológica 
relacionada à fase termofílica do composto e a diminuição no processo de respiração microbiológica na fase de maturação da compostagem.

Tabela 1. Variação das concentrações de Nitrogênio Total (\%) durante 45 dias de compostagem com resíduos de laranja e poda.

\begin{tabular}{|c|c|c|}
\hline Tempo & Laranja & Poda \\
\hline 0 & 2,4 & 1,0 \\
\hline 30 & 2,0 & 0,3 \\
45 & 2,0 & 1,0 \\
\hline
\end{tabular}

Tabela 2. Variação do Potencial Hidrogeniônico durante 45 dias de compostagem com resíduos de casca de laranja e poda.

\begin{tabular}{|l|l|l|}
\hline Tempo & Laranja & Poda \\
\hline 0 & 8,4 & 6,5 \\
\hline 30 & 6,7 & 7,2 \\
\hline 45 & 8,4 & 7,3 \\
\hline
\end{tabular}

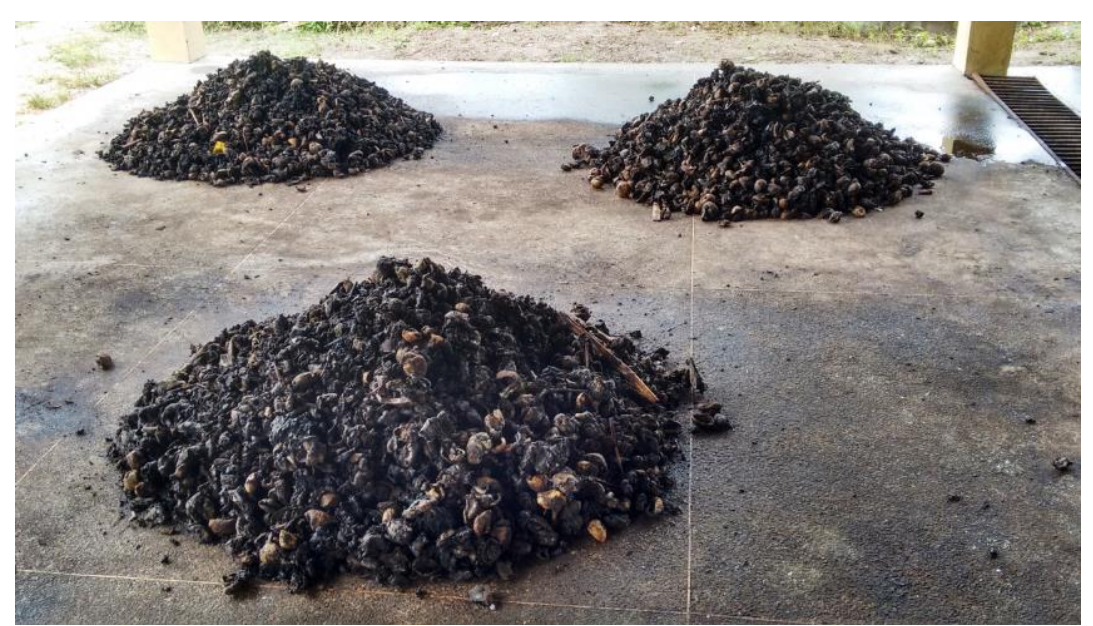

Figura 1 - Três pilhas de Laranja. Experimento com casca de laranja submetida à Compostagem por 45 dias.

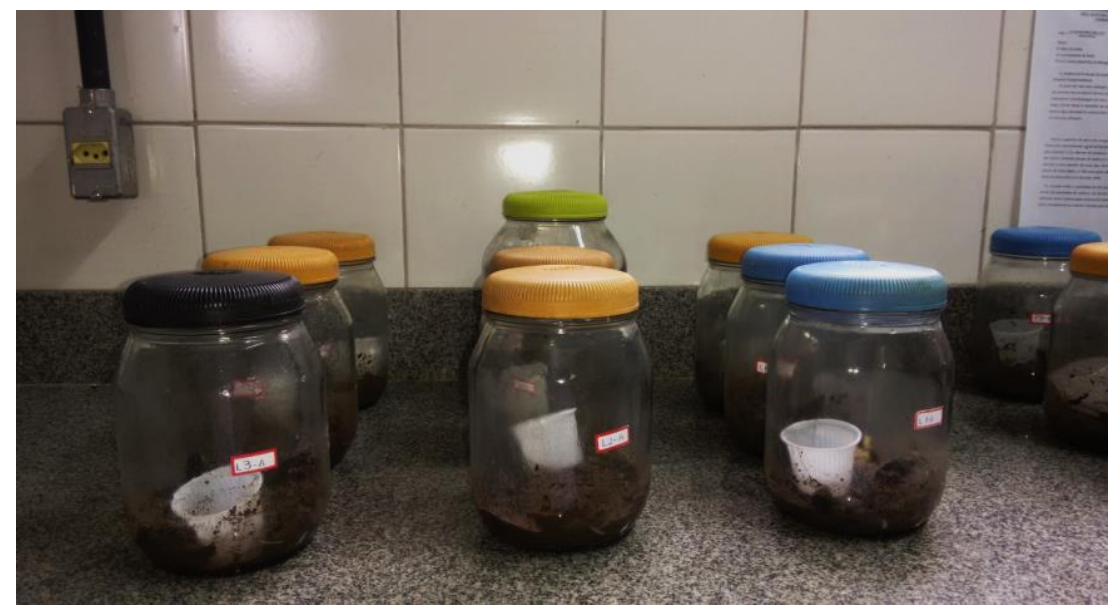

Figura 3- Experimento de Respirometria com amostras de material orgânico submetido a compostagem (Branco, Controle (Solo puro), Tratamento 1 (Compostagem de Casca de Laranja) e Tratamento 2 (Compostagem de Resíduo de Poda). 


\section{CONSIDERAÇÕES FINAIS (ou Conclusão)}

Analisando o desempenho dos parâmetros pH, Nitrogênio Total e Carbono Total pensase que os resíduos de casca de laranja demonstram maior facilidade de decomposição do que os resíduos da poda, quando a compostagem acontece em condições favoráveis. Já que possui uma maior quantidade de nutrientes e microrganismos em sua pilha, as análises da casca da laranja alcançaram uma maior quantidade de carbono e nitrogênio, no entanto, de acordo com Lasardi e Stentiford (1998), o pH desfavorável da laranja pode ter provocado algumas limitações no teste respirométrico. A Poda por sua vez, embora necessite de maior tempo para sua decomposição, também se apresenta como um ótimo composto para o solo.

Quanto aos ensaios respirométricos observou-se uma maior atividade microbiológica no Tempo 30 dias para o Tratamento casca de laranja o que pode ser relacionado a Fase Termofílica da Compostagem. Ficou também evidenciado a similaridade entre as curvas nos períodos de maturação do composto.

\section{REFERÊNCIAS}

NUNESMAIA, F. M. A GESTÃO DE RESÍDUOS URBANOS E SUAS LIMITAÇÕES. COMPANHIA DE TECNOLOGIA DE SANEAMENTO AMBIENTAL - CETESB. Relatório de qualidade das águas interiores do estado de São Paulo. São Paulo, 2004. 264 p.

PEREIRA, R. A. AVALIAÇÃO DA QUALIDADE DA ÁGUA SUPERFICIAL NA ÁREA DE INFLUÊNCIA DE UM LIXÃO. Revista Ambiente \& Água. Universidade Federal do Amazonas, 2013.

VAZ, L. M. S. APLICAÇÃO BIOTECNOLÓGICA DE MICRORGANISMOS TERMOFÍLOS ORIUNDOS DE INDÚSTRIA DE CERVEJA: OBTENÇÃO DE INOCULO MICROBIOLÓGICO PARA COMPOSTAGEM. Feira de Santana; Universidade Estadual de Feira de Santana, 2012, 118 p.Tese (Doutorado em Biotecnologia) - Feira de Santana-Ba, 2012.

POLÍTICA NACIONAL DE RESÍDUOS SÓLIDOS (PNRS), Lei $\mathrm{n}^{\circ}$ 12.305, de 2 de Agosto de 2010, trecho disponível em: http://www.eq.ufrj.br/graduacao/aulas/eqb485_denizedias/2012/ema.pdf

MINISTÉRIO DO MEIO AMBIENTE (MMA); Planos Estaduais de Resíduos Sólidos; 2011.

EMPRESA BRASILEIRA DE PESQUISA AGROPECUÁRIA - EMBRAPA. Manual de Análises Químicas de Solos, Plantas e Fertilizantes. 2ª ed, Brasília, 2009.

GOVERNO FEDERAL - MINISTÉRIO DO MEIO AMBIENTE; Plano Nacional de Resíduos Sólidos; Brasília, Setembro, 2011. (Versão Preliminar para Consulta Pública). Disponível em: http://www.mma.gov.br/estruturas/253/_publicacao/253_publicacao02022012041757.p df Acessado em 07/05/2015 